\title{
High-Contrast Laser Marking of Microelectronic Packaging Modules
}

\author{
N. Liu ${ }^{1}$, Kh. Moumanis ${ }^{1}$, D. Carrier ${ }^{1}$, M. Bilodeau ${ }^{2}$, V. Pomerleau ${ }^{2}$, B. Foisy ${ }^{2}$, J.J. Dubowski ${ }^{1 *}$, \\ ${ }^{1}$ Laboratory for Quantum Semiconductors and Photon-based BioNanotechnology, Interdisciplinary \\ Institute for Technological Innovation (3IT), Université de Sherbrooke, Québec J1K 2R1, Canada, \\ ${ }^{2}$ Centre de Collaboration MiQro Innovation (C2MI), IBM Canada Ltd, Bromont, Quebec, J2L 1A3, \\ Canada \\ *E-mail:jan.j.dubowski@usherbrooke.ca
}

\begin{abstract}
Laser marking is an attractive technique allowing high-speed and high spatial resolution identification of materials, mechanical parts, tools or packaging modules for traceability, advertising, security or trademark protection reasons. The laser marking process, however, is very sensitive to the chemical composition, physical properties and texture of processed surfaces. We have investigated the role of surface chemistry and morphology of nickel-plated copper lids in achieving high optical contrast marking with a Q-switch Nd:YAG laser. Profilometry, scanning electron microscopy and xray photoelectron spectroscopy measurements have been carried out to characterize investigated samples. The results indicate that a low-contrast marking results from a poor ability of the laser to nanostructure the thermally unstable $\mathrm{Ni}(\mathrm{OH})_{2}$-rich surface. The primary mechanism of high-quality marking is related to laser-induced smoothing of the surface and not to the modification of the chemical composition of the irradiated material. However, thermal processing of the lids in air or $\mathrm{N}_{2}$ environments in the $300-350{ }^{\circ} \mathrm{C}$ range, before laser irradiation, has a pronounced effect on the chemical composition as well as on the color of the nickel-plated lids. Laser marking of such colormodified lids leads to drastically improved both resolution and contrast of the process.
\end{abstract}

DOI: $10.2961 / \mathrm{jlmn} .2015 .02 .0013$

Keywords: Laser marking, Q-switch Nd:YAG laser, nickel plating, IC packaging, X-ray photoelectron spectroscopy, nickel oxide

\section{Introduction}

The marking of metal-based packaging modules designed for holding microelectronic circuits is an important step in the device fabrication processes and in providing valuable information both to the manufacturers and their clients. Conventional methods of marking, such as those based on ink-jet printing, suffer from the drawbacks related to the cost of consumables, durability of marking and flexibility of the process [1]. With the introduction of lasers in 1960s, many investigations have been carried out into the laser ability to mark engineering materials. Laser marking of microelectronic modules and packages is a technique used in the microelectronics industry to identify production lots and, e.g., manufacturing dates. The aim of the laser marking is to perform a permanent trace on the surface of the material in order to make it readable and recognizable. Laser marking has advanced systematically over recent 30 years, replacing inkjet marking in many cases due to its high speed and inherent flexibility [2]. In that context, marking of nickel plated packages of integrated circuits (IC) continues to grow and is clearly one of the most diverse market segments. Magnetic properties, corrosion resistance and solderability of nickel plating are properties that have contributed the most to this success [3]. Among various parameters affecting the appearance of laser marked surfaces, the uncontrollable surface morphology and chemistry modification of different substrates could be the source of a reduced contrast marking. The related stud- ies have investigated laser parameters, such as laser beam scanning speed, line width, frequency and power [4]. Fewer works have focused on investigation of the influence of surface morphology and surface chemical composition on the quality of laser marking [5].

We have investigated a series of nickel-plated $\mathrm{Cu}$ lids of IC packaging modules with the goal to determine the origin of a variable quality of laser marking produced with a Qswitch Nd:YAG laser. The focus of our study was surface morphology and surface chemistry of the investigated lids before and after laser irradiation.

\section{Experiments}

A total of $24 \mathrm{Ni}$-plated $(2.5-7.6 \mu \mathrm{m}) \mathrm{Cu}$ lids of IC packaging modules were investigated in this work. The laser marking of original lids was carried out with a Q-switch Nd:YAG laser (RSM 50D, Rofin-Sinar) operating at $26 \mathrm{~A}$ and a $7 \mathrm{kHz}$ repetition rate. The marking was achieved by employing an f-theta lens system with X-Y computer controlled scanning at $200 \mathrm{~mm} / \mathrm{s}$. Thermally processed (annealed) lids were marked with a similar Q-switch laser (Qmark, Quantronix) operating between 21 and 28 A and at 1 to $21 \mathrm{kHz}$ to maintain a fluence of $1 \mathrm{~mJ} /$ pulse [6]. The laser beam scanning speed was adjusted in the range of $400 \sim 1000 \mathrm{~mm} / \mathrm{s}$ to maintain overlap of $25 \mu \mathrm{m}$ between 200 $\mu \mathrm{m}$ diameters spots. The average brightness intensity (gray level) of the marked and unmarked regions was obtained from the analysis of microscopic images of the laser 
marked samples. The optical contrast was calculated from the ratio of gray levels of marked and unmarked regions [4].

A stylus surface profilometer (Dektak 150, Veeco Instruments, Inc.) was used to measure surface roughness of the samples. The measurements were taken using a $2.5 \mu \mathrm{m}$ radius stylus with a $3.0 \mathrm{mg}$ contact force at $3.3 \mu \mathrm{m} / \mathrm{s}$ scan speed. Low-resolution 3D maps were obtained by scanning a length of $100 \mu \mathrm{m}$ in $\mathrm{X}$ direction with a $4 \mu \mathrm{m}$ stepping in $\mathrm{Y}$ direction. These 3D maps provided a clear picture of surface morphology of $100 \mu \mathrm{m} \times 100 \mu \mathrm{m}$ regions characterized by the root-mean-square (RMS) roughness, Rq. More detailed analysis of surface morphology was obtained by collecting scanning electron microcopy (SEM) images with a Supra 55 SEM microscope operating at $15 \mathrm{keV}$.

Surface chemistry has been investigated with the X-ray photoelectron spectroscopy (XPS) technique employing a Kratos Analytical, AXIS Ultra DLD spectrometer equipped with a $150 \mathrm{~W} \mathrm{Al} \mathrm{K \alpha}$ source and operating at a base pressure of $1 \times 10^{-9}$ Torr. The surface survey and high resolution scans were observed in constant energy modes with 50 and $20 \mathrm{eV}$ pass energy filters, respectively. The size of an analyzed area on the investigated samples was set at $220 \mu \mathrm{m} \mathrm{x}$ $220 \mu \mathrm{m}$. The XPS spectra were recorded for samples after laser irradiation and after annealing in a conventional furnace. The collected data were processed using Casa XPS 2.3.15 software. To compensate for the surface charging effect, all XPS data binding energies were referenced to the adventitious $\mathrm{C}\left(\mathrm{C}_{\mathrm{adv}}\right) 1 \mathrm{~s}$ peak at the $\mathrm{BE}$ of $285.0 \mathrm{eV}$.

\section{Results and Discussion}

\subsection{Laser marking contrast investigation}

Fig. 1 shows microscopic image of sample No 2 with low contrast (a) and sample No 11 with high contrast (b) marking. It clearly shows a superior contrast between marked and unmarked regions on sample No 11. The laser marked region on sample No 2 is only weakly distinguishable from the initial (unmarked) region.

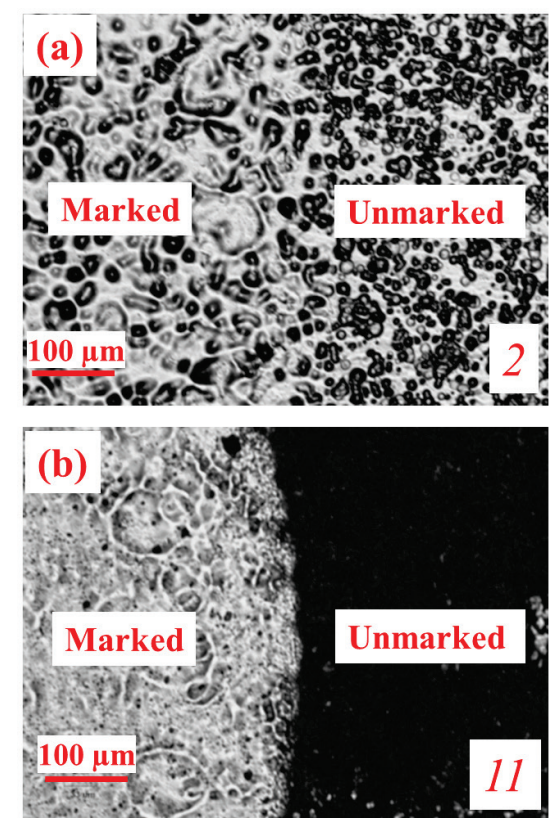

Fig. 1 Microscopic images of sample No 2 with low contrast (a) and sample No 11 with high contrast (b) laser marking.
Table 1 summarizes gray scale intensities (GSI) of 6 samples selected from the group of investigated samples (No. 11, 14, 18, 5, 17 and 2). It can be seen that sample No 11 exhibits the largest intensity ratio between the unmarked and laser marked regions, while sample No 2 shows the weakest laser marking contrast.

Table 1 Intensity of marked and unmarked regions of 6 samples selected from the pool of 24 samples.

\begin{tabular}{cccc}
\hline Sample No & \multicolumn{2}{c}{ GSI } & $\begin{array}{c}\text { GSI ratio } \\
\text { Mrk/Unk }\end{array}$ \\
\cline { 2 - 3 } & Marked & Unmarked & 2.97 \\
11 & 172 & 58 & 2.92 \\
14 & 207 & 71 & 1.43 \\
18 & 157 & 110 & 1.38 \\
5 & 196 & 142 & 1.27 \\
17 & 122 & 96 & 1.25 \\
2 & 144 & 115 & \\
\hline
\end{tabular}

\subsection{Surface morphology investigation}

In order to investigate the effects of surface morphology on the achievable laser marking contrast, we compare in Table 2 the $R_{\mathrm{q}}$ values for the samples discussed in Table 1 . Sample No 11, which exhibits the largest marking contrast, also shows the lowest roughness of the laser marked region. At the same time, sample No 2, which exhibits the poorest marking contrast, shows the highest roughness of the laser marker region. Generally, it seems that the increasing ratio of $\mathrm{R}_{\mathrm{q}}{ }^{\text {Mrk }} / \mathrm{R}_{\mathrm{q}}{ }^{\text {Unk }}$ is associated with the decreasing contrast of laser marking. The samples from the poor marking contrast group (No 18, 5, 17 and 2) are characterized by relatively high values of $\mathrm{R}_{\mathrm{q}}$ Unk . However, as discussed in Sec. 3.3, the samples from this group exhibit also an excessive concentration of $\mathrm{Ni}(\mathrm{OH})_{2}$ that is drastically reduced following the irradiation with the laser. For such samples, laser induced surface morphology cannot be separated from a modification of its chemical composition. In contrast, the surface of chemically more stable and initially (chemically) nanostructured samples exhibit high marking contrast, as observed in Fig. 1b. The interaction of a laser with such samples (No 11 and 14) leads to smoothing of their surfaces that reflect white light with an increased efficiency.

Table 2 Root-mean-square $\left(\mathrm{R}_{\mathrm{q}}\right)$ roughness of as-received (unmarked) and laser marked samples.

\begin{tabular}{cccc}
\hline Sample No & \multicolumn{2}{c}{$\mathrm{R}_{\mathrm{q}}(\mathrm{nm})$} & $\mathrm{R}_{\mathrm{q}}^{\text {Mrk }} /$ \\
\cline { 2 - 4 } & Marked & Unmarked & $\mathrm{R}_{\mathrm{q}}^{\text {Unk }}$ \\
\hline 11 & 352 & 547 & 0.6 \\
14 & 334 & 541 & 0.6 \\
18 & 636 & 956 & 0.7 \\
5 & 481 & 478 & 1.0 \\
17 & 602 & 670 & 0.9 \\
2 & 793 & 719 & 1.1 \\
\hline
\end{tabular}

Fig. 2 shows SEM images of non-processed and laser marked surfaces of samples No 14, 5, and 17. Based on the contrast and surface morphology measurements in Table 1 and Table 2, the marking quality decreases from sample No 14 and 5 to 17 . Note the differences in the surface mor- 
phology of non-processed regions: the roughest initial surface characterizes the worst laser marking quality sample. On the processed regions of samples No 14 and 5, a series of laser fabricated spots can be seen quite clearly. The spots on the sample No 17, however, are almost invisible.

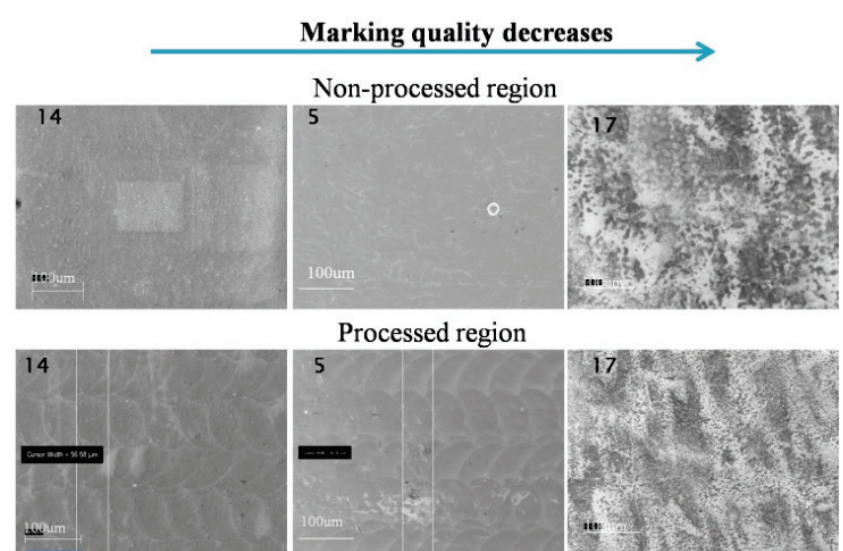

Fig. 2 SEM images of non-processed and processed regions of samples No 14, 5 and 17.

\subsection{Surface chemical investigation}

Fig. 3 shows the $\mathrm{Ni} 2 \mathrm{p} 3 / 2$ XPS spectra of nonprocessed and processed regions of the sample No 14, which belongs to the group of samples exhibiting a good quality laser marking. The spectra are fitted with the asymmetric line shape and plasmon loss peaks for Ni metal (red) and an empirical fit of the $\mathrm{NiO}$ (green) and $\mathrm{Ni}(\mathrm{OH})_{2}$ (blue) line shapes [7]. The offset of the higher binding energy end of the background was used to improve the fit of the peak shapes. This background offset is determined using an iterative approach while monitoring a residual plot of the 2 p $3 / 2$ area [8]. Peak positions of these chemical compounds are presented in Table 3.

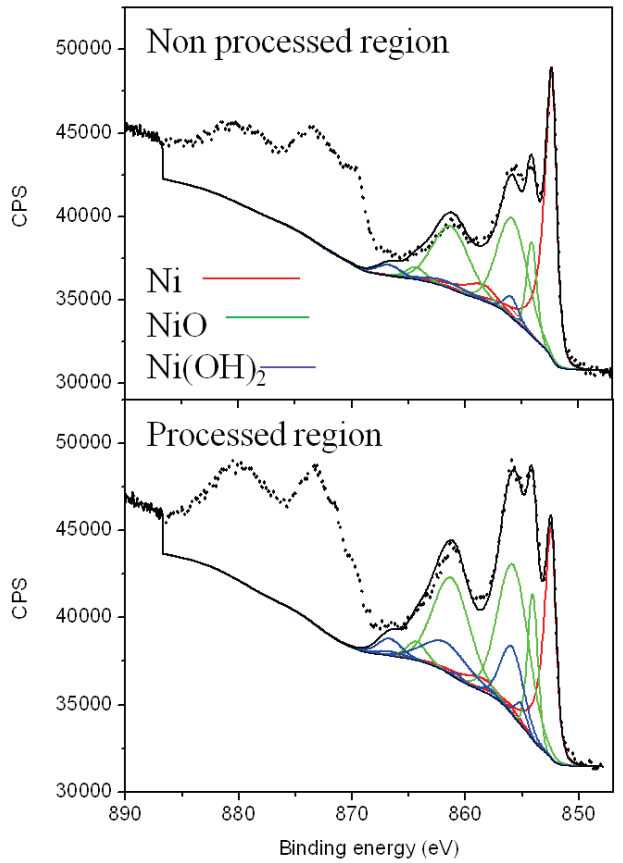

Fig. $3 \mathrm{Ni}$ XPS spectra of non-processed and processed regions of sample 14. The XPS data envelope is shown with a dotted line (...) and the results of fitting are shown with a solid black line (-).
Table 3 Binding energy of chemical compounds used to fit the Ni 2 p $3 / 2$ spectrum.

\begin{tabular}{|c|c|c|c|c|c|c|}
\hline & $\begin{array}{c}\text { Peak } \\
1 \\
(\mathrm{eV}) \\
\end{array}$ & $\begin{array}{c}\text { Peak } \\
2 \\
(\mathrm{eV})\end{array}$ & $\begin{array}{c}\text { Peak } \\
3 \\
(\mathrm{eV}) \\
\end{array}$ & $\begin{array}{c}\text { Peak } \\
4 \\
(\mathrm{eV}) \\
\end{array}$ & $\begin{array}{c}\text { Peak } \\
5 \\
(\mathrm{eV})\end{array}$ & $\begin{array}{c}\text { Peak } \\
6 \\
(\mathrm{eV}) \\
\end{array}$ \\
\hline $\mathrm{Ni}$ & 852.4 & 856.0 & 858.4 & & & \\
\hline $\mathrm{NiO}$ & 854.1 & 855.8 & 861.2 & 864.3 & 866.7 & \\
\hline $\mathrm{Ni}(\mathrm{OH})_{2}$ & 855.1 & 855.9 & 857.9 & 860.7 & 861.7 & 866.7 \\
\hline
\end{tabular}

The atomic percentage of $\mathrm{Ni}, \mathrm{NiO}$ and $\mathrm{Ni}(\mathrm{OH})_{2}$ for non-processed and processed regions of the sample No 14 is shown in Table 4. These results indicate the increasing concentration of $\mathrm{NiO}$ and $\mathrm{Ni}(\mathrm{OH})_{2}$ on the laser processed sites.

Table 4 Atomic percentage of $\mathrm{Ni}, \mathrm{NiO}$ and $\mathrm{Ni}(\mathrm{OH})_{2}$ of nonprocessed and processed regions of the sample No 14.

\begin{tabular}{cccc}
\hline & $\mathrm{Ni}$ & $\mathrm{NiO}$ & $\mathrm{Ni}(\mathrm{OH})_{2}$ \\
\hline Non-processed & 25.52 & 54.80 & 19.68 \\
Processed & 18.96 & 58.24 & 22.81 \\
\hline
\end{tabular}

In Table 5, we present atomic percentage of $\mathrm{Ni}, \mathrm{NiO}$ and $\mathrm{Ni}(\mathrm{OH})_{2}$ observed on non-processed regions of the samples No 14, 5, 9 and 17 that are listed in an order representing a decreasing laser marking quality. It can be seen that the increasing concentration of $\mathrm{Ni}(\mathrm{OH})_{2}$ coincides with a decreased quality marking.

Table 5 Atomic percentage of $\mathrm{Ni}, \mathrm{NiO}$ and $\mathrm{Ni}(\mathrm{OH})_{2}$ on the asreceived surface of selected samples. The intensity ratio was calculated based on gray scale of the as-received and laser marked material.

\begin{tabular}{ccccc}
\hline Sample & GSI ratio & $\mathrm{Ni}$ & $\mathrm{NiO}$ & $\mathrm{Ni}(\mathrm{OH})_{2}$ \\
\hline 14 & 2.92 & 25.52 & 54.80 & 19.68 \\
5 & 1.38 & 27.06 & 38.86 & 36.83 \\
9 & 1.29 & 15.71 & 35.16 & 48.56 \\
17 & 1.27 & 20.98 & 28.57 & 48.18 \\
\hline
\end{tabular}

For comparison, the concentration of $\mathrm{Ni}, \mathrm{NiO}$ and $\mathrm{Ni}(\mathrm{OH})_{2}$ on the surface of laser irradiated samples No 14,5 , 9 and 17 are listed in Table 6. It can be seen that the chemical composition of all the samples are similar and no trend could be observed that would correspond to the decreasing/increasing contrast of laser marking.

Table 6 Atomic percentage of $\mathrm{Ni}, \mathrm{NiO}$ and $\mathrm{Ni}(\mathrm{OH})_{2}$ on the laser processed surface of selected samples.

\begin{tabular}{ccccc}
\hline Sample & GSI ratio & $\mathrm{Ni}$ & $\mathrm{NiO}$ & $\mathrm{Ni}(\mathrm{OH})_{2}$ \\
\hline 14 & 2.92 & 18.96 & 58.24 & 22.81 \\
5 & 1.38 & 18.56 & 66.15 & 15.41 \\
9 & 1.29 & 18.86 & 57.15 & 23.26 \\
17 & 1.27 & 15.14 & 66.90 & 15.94 \\
\hline
\end{tabular}

Based on these results, we conclude that the high quality marking observed for the sample No 14 is not due to the differences in surface chemical composition between as received and laser processed surfaces. The laser smoothing of the surface appears in this case to be the main reason of the observed laser marking contrast. However, a drastic reduction of $\mathrm{Ni}(\mathrm{OH})_{2}$ has been observed on the surface of 
laser irradiated samples exhibiting poor quality marking (No 5, 9, 17). Surface roughness of such samples remained relatively unaffected by irradiation with the laser, as observed in Table 1 for the samples No 5 and 17, or even increased following the laser irradiation, as observed for sample No 2 .

\subsection{Thermal processing before laser marking}

Since the excessive concentration of $\mathrm{Ni}(\mathrm{OH})_{2}$ on the asreceived surfaces of the investigated lids was found related to poor quality marking, we have also investigated laser marking of samples that were thermally processed to reduce $\mathrm{Ni}(\mathrm{OH})_{2}$ known to decompose at temperatures exceeding $300^{\circ} \mathrm{C}$ [9]. Table 7 compares the XPS results obtained for samples before and after heating at 300 and $350{ }^{\circ} \mathrm{C}$ in $\mathrm{N}_{2}$ and air for 20 minutes. It shows that the annealing even at $300{ }^{\circ} \mathrm{C}$ drastically reduces surface concentration of $\mathrm{Ni}(\mathrm{OH})_{2}$. At the same time, a 2.7-fold and 3-fold increase of $\mathrm{NiO}$ has been observed.

Table 7 Atomic percentage of $\mathrm{Ni}, \mathrm{NiO}$ and $\mathrm{Ni}(\mathrm{OH})_{2}$ on the surface of as-received and annealed samples at 300 and $350^{\circ} \mathrm{C}$ for 20 minutes in $\mathrm{N}_{2}$ and air.

\begin{tabular}{cccc}
\hline & $\mathrm{Ni}$ & $\mathrm{NiO}$ & $\mathrm{Ni}(\mathrm{OH})_{2}$ \\
\hline Before heating & 20.98 & 28.57 & 48.18 \\
Heating at $300^{\circ} \mathrm{C}$ in $\mathrm{N}_{2}$ & 0.24 & 76.31 & 23.44 \\
Heating at $350^{\circ} \mathrm{C}$ in $\mathrm{N}_{2}$ & 0.5 & 76.97 & 22.45 \\
Heating at $300^{\circ} \mathrm{C}$ in air & 0.24 & 83.84 & 15.93 \\
Heating at $350^{\circ} \mathrm{C}$ in air & 0.23 & 87.59 & 13.68 \\
\hline
\end{tabular}

In addition to significant changes of the chemical composition, the samples annealed at $350{ }^{\circ} \mathrm{C}$ exhibited significant transformation of their color. Fig. 4 shows optical image of a reference sample (before heating) and samples annealed in air at $300^{\circ} \mathrm{C}$ (Air $300 \mathrm{deg}$ ) and $350^{\circ} \mathrm{C}$ (Air 350 deg) and in $\mathrm{N}_{2}$ at $300^{\circ} \mathrm{C}$ (Nitrogen $300 \mathrm{deg}$ ) and $350^{\circ} \mathrm{C}(\mathrm{Ni}-$ trogen 350deg). It can be seen that the sample annealed in $\mathrm{N}_{2}$ underwent their color change from silver to light blue (Nitrogen 300deg) and to deep blue (Nitrogen 350deg). In comparison, the samples annealed in air, underwent their color changed from silver to light yellow (Air 300deg) and deep yellow (Air 350deg). As illustrated in Fig. 4, laser marking of thermally processed samples, especially those annealed at $350^{\circ} \mathrm{C}$, produced clearly visible marks with a contrast far exceeding that of any of the high-quality marks fabricated on as-received samples.

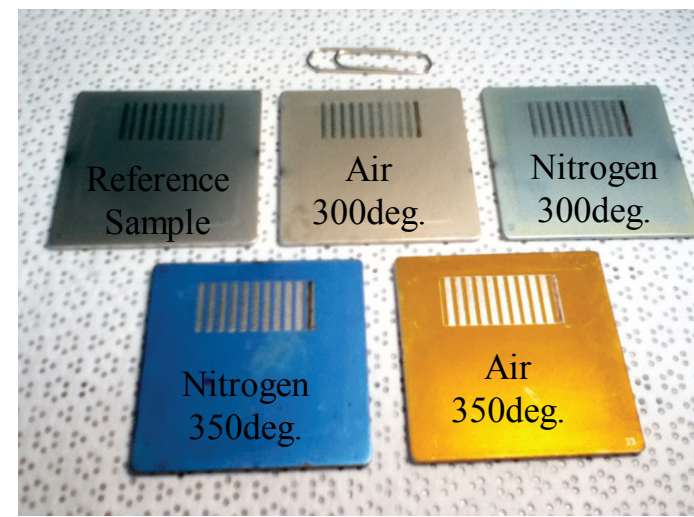

Fig. 4 Images of a reference sample and samples heated in air and $\mathrm{N}_{2}$ at $300^{\circ} \mathrm{C}$ and $350^{\circ} \mathrm{C}$
Nickel oxide has been widely studied as an electrochromatic material undergoing color transformation during $\mathrm{OH}$ desorption induced by reactions involving ion injection and heating [10]. The oxide rich films have been reported to be fully colored while the reduced oxidation films are bleached or transparent [11]. We employed XPS measurements to investigate the origin of color transformation and study $\mathrm{NiO} / \mathrm{Ni}(\mathrm{OH})_{2}$ ratio in thermally treated material [12].

Fig. 5 shows the Ni $2 p$ XPS spectra of the non-marked yellow (Air 350deg) and blue (Nitrogen 350deg) samples. It can be seen that, in comparison with Fig. 3, the quantity of metal $\mathrm{Ni}$ at $852.4 \mathrm{eV}$ in the yellow material has diminished to near the background level. Furthermore, all five peaks of $\mathrm{NiO}$ (with binding energies listed in Table 3) show increased intensities while slightly reduced intensities of $\mathrm{Ni}(\mathrm{OH})_{2}$ related peaks have also been observed.

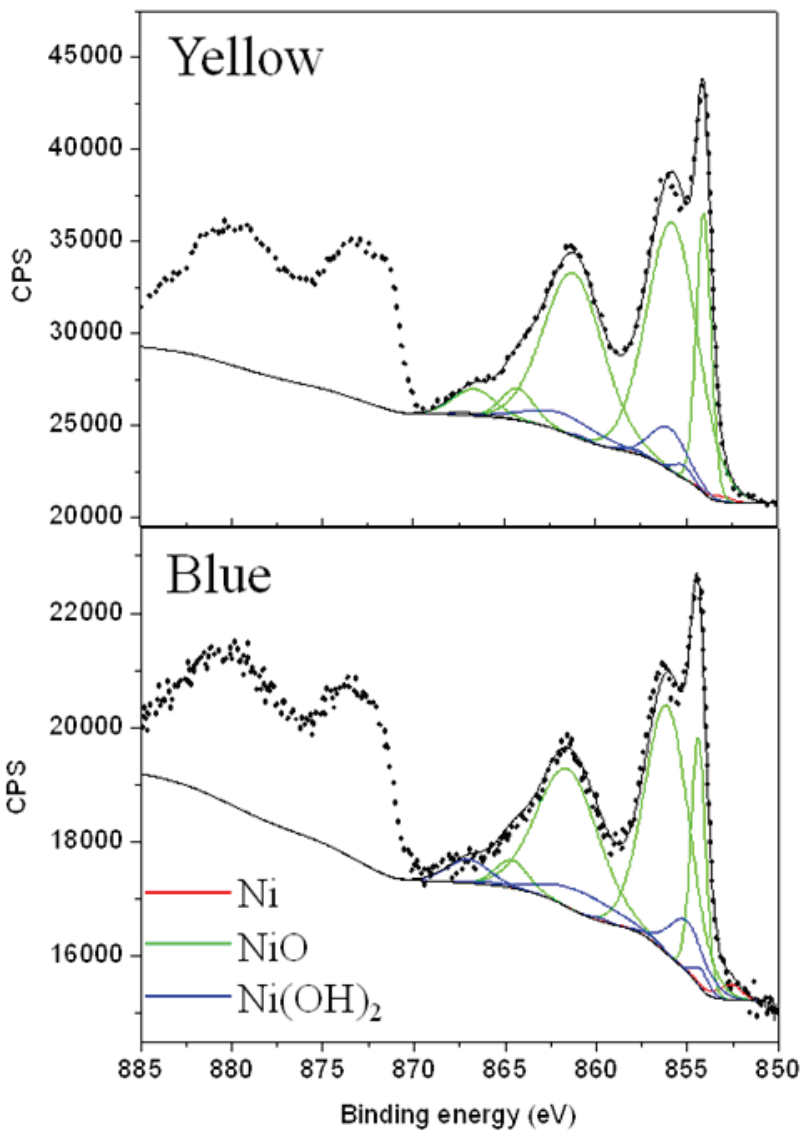

Fig. 5 Ni 2p XPS spectra of yellow and blue surfaces. The XPS data envelope is shown with a dotted line (...) and the results of

fitting are shown with a solid black line (-).

Fig. 6 shows the O 1s XPS spectra of non-marked region on the reference, yellow and blue samples surfaces. The dash-line peaks in the region of $530-536 \mathrm{eV}$ originate from the oxygen bonded to $\mathrm{C}$ adsorbates on the surface [13, [14]. The NiO components include two major O peaks assigned at 529.8 and $531.3 \mathrm{eV}$. The first peak corresponds to $\mathrm{O}$ bonded to a regular $\mathrm{Ni}$ oxide crystal and the second peak corresponds to oxygen atoms in positions adjacent to $\mathrm{Ni}$ vacancies $(\mathrm{NiO}(\mathrm{def}))$ within the oxide structure. The peak at $531.4 \mathrm{eV}$ is assigned to hydroxide bonded to nickel: $\mathrm{Ni}\left(\mathrm{OH}^{-}\right)$. The peak at $532.9 \mathrm{eV}$ on the reference sample is 
assigned to $\mathrm{H}_{2} \mathrm{O} / \mathrm{O}_{2}$ remaining on the surface. The peak at $532.6 \mathrm{eV}$ in the blue sample originates from the nitrate nickel oxides formed during heating in the $\mathrm{N}_{2}$ environment. From Fig. 5 and 6 , it is estimated that the ratio of $\mathrm{NiO} / \mathrm{Ni}(\mathrm{OH})_{2}$ is 6.4 and 3.42 on yellow and blue surface, respectively, which compares to 0.59 observed for the reference silver-like sample.

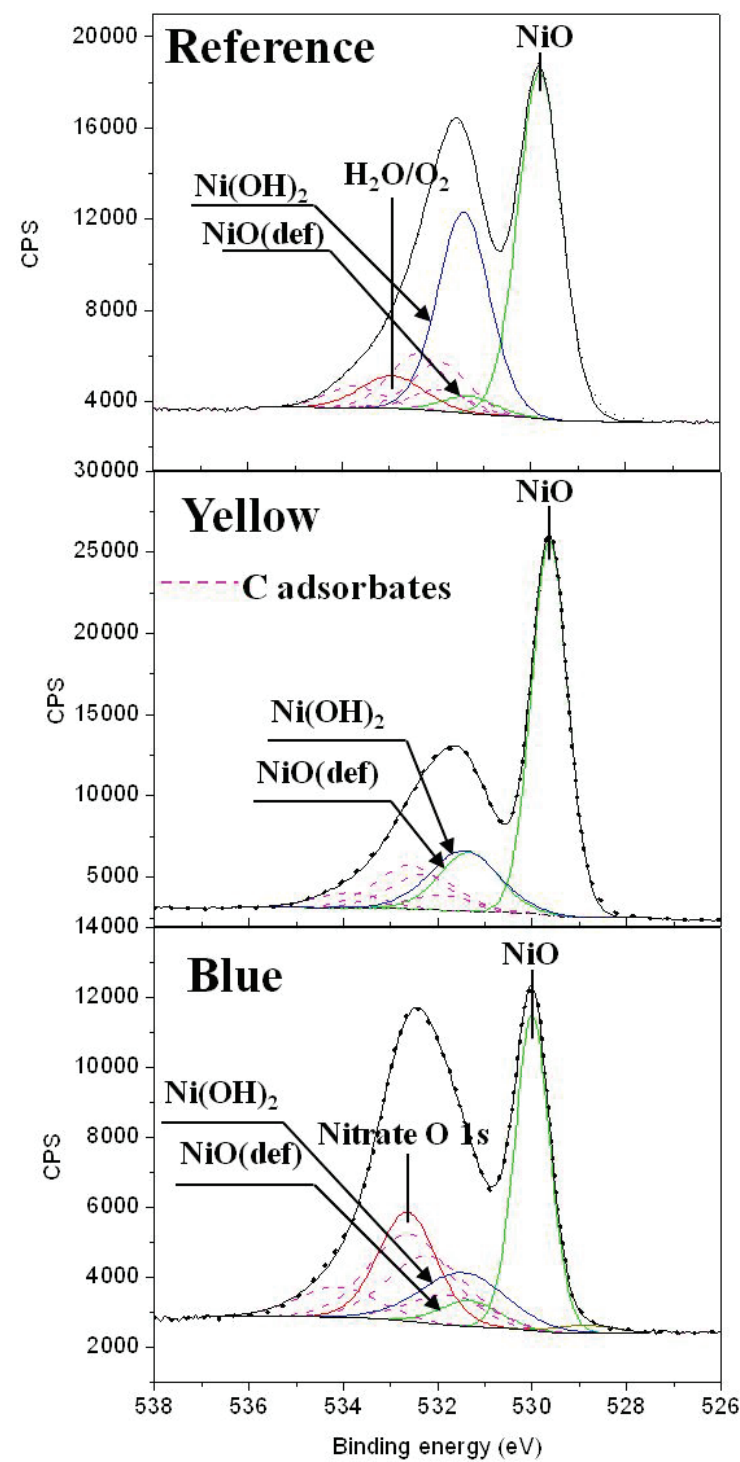

Fig. 6 O 1s XPS spectra of non-marked region of yellow and blue surfaces. The XPS data envelope is shown with a dotted line (...)

and the results of fitting are shown with a solid black line (-).

It has been reported that normally transparent (bleached) thin films of $\mathrm{Ni}(\mathrm{OH})_{2}$ undergo oxidation in an $\mathrm{OH}^{-}$environment that results in formation of yellow to brown films absorbing light in the visible region of the spectrum [11]:

\section{$\mathrm{Ni}(\mathrm{OH})_{2}$ (bleached) $+\mathrm{OH}^{-} \rightarrow \mathrm{NiO}(\mathrm{OH})$ (colored) $+\mathrm{H}_{2} \mathrm{O}+\mathrm{e}^{-}$}

The nickel oxide/hydroxides mixture has been described by $\mathrm{NiO}(\mathrm{OH})$ with octahedral nickel-oxygen coordination [12]. The formation of pale blue $\mathrm{NiO}_{\mathrm{x}}$ films has also been observed with an electrolytic process followed by chemical vapor deposition [12]. These experiments have revealed that the bleached state and film coloration depend on the number of $\mathrm{Ni}(\mathrm{OH})_{2}$ sites lacking in water molecules and extraction/insertion of protons and water molecules in the structure of these films.

In the marked region, the XPS ratios of $\mathrm{NiO} / \mathrm{Ni}(\mathrm{OH})_{2}$ were reduced from 6.4 to 2.81 and 3.42 to 2.72 on the yellow and blue substrates, respectively. In the marked region of the samples preheated at $300{ }^{\circ} \mathrm{C}$, those ratios were reduced from 5.26 to 2.97 for the samples annealed in air, and from 3.26 to 2.92 for the samples annealed in $\mathrm{N}_{2}$ (data not shown here). Thus the $\mathrm{NiO} / \mathrm{Ni}(\mathrm{OH})_{2}$ ratio in the marked region of annealed samples $(2.72-2.97)$ and of the highquality laser marked as-received sample No 14 (2.6) fall in the close range of chemical compositions. It is interesting to note that the laser irradiation of as-received and $300{ }^{\circ} \mathrm{C}$ annealed samples yields surfaces that, observed under a near normal incidence, reflect more efficiently white light than the non-irradiated surface. The opposite effect is observed under a grazing incidence angle, as illustrated in Fig. 4, which indicates laser-induced formation of a diffusively scattering surface. However, laser marking of the blue and yellow lids produced smooth surfaces that appear always brighter to the eye, regardless of the observation angle.

\section{Conclusion}

The results of this study have indicated that nonuniformly Ni-plated $\mathrm{Cu}$ lids of microelectronic packaging modules could result in a poor quality laser marking not correctable by varying laser parameters. Thermal annealing at $350^{\circ} \mathrm{C}$ of the as-fabricated lids produces their coloration. The annealing in air yields yellow material, while annealing in $\mathrm{N}_{2}$ yields blue material. This color change is related to decomposition of $\mathrm{Ni}(\mathrm{OH})_{2}$ and extraction/insertion of protons and water molecules in the structure of the films. Thermal processing of Ni-plated lids offers attractive conditions for high-contrast and high-resolution laser marking with the Q-switch Nd:YAG laser.

\section{Acknowledgement}

This work was supported by the Natural Science and Engineering Research Council of Canada Engage Grant No. EGP 437014 - 12, Discovery Grant No. 122795-2010 and the program of the Canada Research Chair in Quantum Semiconductors (JJD). The authors are indebted to $\mathrm{Mr}$. David Danovitch for fruitful discussions. Technical assistance of the Université de Sherbrooke Centre de caracterization de materiaux (CCM) in collecting XPS data and the Centre de recherche en nanofabrication et en nanocaracterisation $\left(\mathrm{CRN}^{2}\right)$ is greatly appreciated.

\section{References}

[1] Y. M. Noor, S. C. Tam, L. E. N. Lim and S. Jana: J. Mater. Process. Technol. 42, (1994) 95.

[2] L. E. Gordon: US Patent 4,922,077, (1990)

[3] J. Sudagar, J. Lian and W. Sha: J. Alloys Compd. 571, (2013) 183.

[4] J. F. Ready, D. F. Farson and T. Feeley: "LIA handbook of laser materials processing: laser marking/branding" ed. by (Laser Institute of America Orlando 2001) p.715.

[5] B. Dusser, Z. Sagan, H. Soder, N. Faure, J.-P. Colombier, M. Jourlin and E. Audouard: Opt. Express 18, (2010) 2913. 
[6] R. Stanowski, O. Voznyy and J. J. Dubowski: JLMN 1, (2006) 17.

[7] M. C. Biesinger, B. P. Payne, A. P. Grosvenor, L. W. Lau, A. R. Gerson and R. S. C. Smart: Appl. Surf. Sci. 257, (2011) 2717.

[8] M. C. Biesinger, B. P. Payne, L. W. Lau, A. Gerson and R. S. C. Smart: Surf. Interface Anal. 41, (2009) 324.

[9] T. Sato, T. Nakamura and F. Ozawa: J. Appl. Chem. Biotechnol. 25, (1975) 583.

[10] D. Wruck and M. Rubin: J. Electrochemi. Soc. 140, (1993) 1097.

[11] M. K. Carpenter, R. S. Conell and D. A. Corrigan: Sol. Energ. Mat. 16, (1987) 333.

[12] M. Chigane and M. Ishikawa: J. Chem. Soc. Faraday Trans. 94, (1998) 3665.

[13] N. Liu and J. J. Dubowski: Appl. Surf. Sci. 270, (2013) 16.

[14] B. P. Payne, M. C. Biesinger and N. S. McIntyre: . Electron. Spectrosc. Relat. Phenom. 184, (2009) 29.

(Received: September 1, 2014, Accepted: March 3, 2015) 